\title{
Organic Solar Cells with Boron- or Nitrogen-Doped Carbon Nanotubes in the P3HT : PCBM Photoactive Layer
}

\author{
Godfrey Keru, ${ }^{1}$ Patrick G. Ndungu, ${ }^{1,2}$ Genene T. Mola, ${ }^{1}$ \\ Ana F. Nogueira, ${ }^{3}$ and Vincent O. Nyamori ${ }^{1}$ \\ ${ }^{1}$ School of Chemistry and Physics, University of KwaZulu-Natal, Westville Campus, Private Bag X54001, Durban 4000, South Africa \\ ${ }^{2}$ Department of Applied Chemistry, University of Johannesburg, P.O. Box 17011, Doornfontein, Johannesburg 2028, South Africa \\ ${ }^{3}$ Chemistry Institute, State University of Campinas, P.O. Box 6154, 13083970 Campinas, SP, Brazil \\ Correspondence should be addressed to Vincent O. Nyamori; nyamori@ukzn.ac.za
}

Received 22 September 2015; Revised 1 December 2015; Accepted 2 December 2015

Academic Editor: Christian Brosseau

Copyright (C) 2016 Godfrey Keru et al. This is an open access article distributed under the Creative Commons Attribution License, which permits unrestricted use, distribution, and reproduction in any medium, provided the original work is properly cited.

\begin{abstract}
Either boron- or nitrogen-doped carbon nanotubes (B- or N-CNTs) were incorporated in bulk heterojunction organic solar cells photoactive layer composed of poly(3-hexylthiophene) (P3HT) : (6,6)-phenyl- $\mathrm{C}_{61}$-butyric acid methyl ester (PCBM). The physical and chemical properties were investigated using different spectroscopic techniques. The cell performance was followed from their current-voltage $(J-V)$ characteristics. Recombination dynamics of the photo-generated free charge carriers were investigated using micro- to milliseconds transient absorption spectroscopy (TAS). Transmission electron microscopy (TEM) images revealed the presence of cone structures and bamboo compartments in B-CNTs and N-CNTs, respectively. X-ray photoelectron spectroscopy (XPS) revealed very little boron was substituted in the carbon network and presence of pyrrolic, pyridinic, and quaternary species of nitrogen in N-CNTs. $J-V$ characteristics were found to be similar for the devices with B-and N-CNTs even though boron- and nitrogen-doped CNTs are known to have different properties, that is, p-type and n-type, respectively. TAS results showed that all devices had long lived free charge carriers but the devices with B- or N-CNTs had low power conservation efficiency and voltage.
\end{abstract}

\section{Introduction}

The demand on energy supply has become a key concern with the advancement and development of nations. The current trend suggests that the future global economy is likely to consume even more energy. At the moment, the main source of energy is still fossil fuels (oil, coal, and gas). However, the dwindling size of global fossil fuel resources compounded with unfavourable climatic changes due to emission of oxides of carbon by the use of these fuels calls for the need to look for an alternative source of energy. Renewable sources which are environmentally friendly and inexhaustible are the best alternative $[1,2]$. Among the renewable resources of energy, solar energy is one of the most abundant resources and can easily be converted to electricity by use of photovoltaic cells [3]. Bulk heterojunction organic solar cells (OSCs) whose photoactive layers are composed of p-type conjugated polymer and fullerene derivatives are the most promising device structure for solar energy conversion. The advantages of using OSCs over others include low device manufacturing cost using solution processing to ultrathin film and flexible and light weight substrates $[4,5]$. Recently, power conversion efficiencies above $10 \%$ have been reported for OSCs [6-8], which is the minimum value required for commercialization of OSC in the energy market [9].

One of the major limitations of OSCs is low diffusion length of the excitons that ranges between 10 and $15 \mathrm{~nm}$ which causes high recombination and low power conversion [10]. This difficulty has been eased by the introduction of bulk heterojunction (BHJ) design in which the donor and acceptor molecules are blended in the photoactive medium. Such mixture of donor-acceptor molecules increases the efficient dissociation of excitons in the medium by creating local donor/acceptor interfaces. Although free charge carrier generation is improved using $\mathrm{BHJ}$, high efficiency cannot be achieved due to the disordered nature of the medium that 
prevents the smooth transport of charges. Instead charges are forced to use percolation paths via a hoping mechanism to reach electrodes [11, 12]. Low charge carrier mobility in the bulk of organic materials can be addressed by the incorporation of one-dimensional nanostructures such as carbon nanotubes (CNTs) which provide a high mobility pathway for charge carriers within the semiconducting materials [13].

CNTs in the photoactive layer of OSC improve not only carrier mobility but also mechanical flexibility of the polymer materials and are also compatible with throughput solution processing [14]. Despite such attractive advantages of CNT, their incorporation in the photoactive layer of OSCs often has resulted in poor performances than those without CNTs [5]. Derbal-Habak et al. [15] investigated the cell efficiency by varying wt.\% SWCNTs, that is, between 0 and $0.6 \mathrm{wt} . \%$ of ester functionalized HiPCo SWCNTs. Their findings indicated that the reduction was directly proportional to the percentage weight ratio of SWCNTs, with $0.6 \mathrm{wt} . \%$ having the highest reduction. Even when CNTs in the photoactive layer are purported to enhance efficiencies, values reported are still very low for commercialization. For instance, Stylianakis and Kymakis [16] reported an improvement from 2.67 to $3.52 \%$ in addition to $0.5 \%$ functionalized single-walled CNTs (SWCNTs). This enhancement was attributed to efficient excitons dissociation and improved hole mobility. Khatri et al. [17] reported enhanced photovoltaic properties by introducing a combination of SWCNTs and functionalized multiwalled CNTs (MWCNTs) in poly(3-octylthiophene) (P3OT)/n-silicon hybrid heterojunction solar cells. SWCNTs assisted in excitons dissociation and electron transfer while MWCNTs in hole transfer. Kuila et al. [18] incorporated CNTs in the polymer matrix by grafting $\mathrm{P} 3 \mathrm{HT}$ on the walls of CNTs via ester bonds and an efficiency of $0.29 \%$ was obtained for this cell.

On the other hand, there have been reports that suggest there are positive effects with the introduction of either BCNTs or N-CNTs in the photoactive layer of OSCs $[11,12]$. The possible reason for this enhancement can be due to the $\mathrm{B}-$ or N-CNTs serving very specific role with regard to the charge transfer in the medium. B-CNTs usually behave as p-type semiconductors with high work function $(-5.2 \mathrm{eV})$ that matches well with the highest occupied molecular orbital (HOMO) of the donor polymer (P3HT) $(-5.1 \mathrm{eV})$ and make them selective to hole transfer [11]. However, NCNTs behave as n-type semiconductor with work function $(-4.2 \mathrm{eV})$ close to the lowest occupied molecular orbital (LUMO) of the receiver materials, which are commonly fullerene derivatives such as 1-(3-methoxycarbonyl)-propyl1-phenyl-[6,6] $\mathrm{C}_{61}(\mathrm{PCBM})(-3.7 \mathrm{eV})$ [11]. It is energetically favourable for electrons to move from the LUMO of the acceptor to N-CNTs; therefore, they are electron selective. For example, Lee et al. [12] reported 13\% increase in efficiency with the incorporation of N-CNTs in the photoactive layer poly(3-hexylthiophene) : indene- $\mathrm{C}_{60}$ bisadduct (P3HT: ICBA/N-CNTs) from 4.68 to $5.29 \%$. The same group had earlier reported high efficiency by incorporating $1.0 \mathrm{wt} . \%$ of either B- or N-CNTs in the photoactive layer of the cell P3HT : PCBM which resulted in an efficiency of $4.1 \%$ and $3.7 \%$ for B- and N-CNTs, respectively. These high efficiencies were attributed to selectivity of charge carrier transport in the medium.

In this paper, we investigated how doping of CNTs with either boron or nitrogen affects the performance of OSCs when incorporated in the photoactive layer of the cell composed of either P3HT/B- or N-CNTs: PCBM. Xray photoelectron spectroscopy (XPS) was used to analyse the elemental composition as well as the chemical bonding environment of boron or nitrogen. Atomic force microscope (AFM) and scanning electron microscope (SEM) were used to determine the morphology of the photoactive film layer. Ultraviolet-visible (UV-Vis) and photoluminescence (PL) were used to determine absorbance and emission, respectively. Transient absorption spectroscopy (TAS) was used to determine the life-time of dissociated charge carriers and the recombination dynamics. TAS is an excellent technique for investigating recombination dynamics in the photoactive layer of a photovoltaic device. To the best of our knowledge, this is the first report on reasons why despite enhancing properties of CNTs by doping with either boron or nitrogen, their performance in OSCs was opposite of the expectation.

\section{Experimental}

2.1. Materials and Methods. Chemicals and solvents used in this study were of analytical grade and used as received unless otherwise stated. Benzyl alcohol (98\%), thionyl chloride (98\%), poly(3-hexylthiophene)2,5-dyl (P3HT) (98\%), 1-(3-methoxylcarbonyl)propyl-1-phenyl-[6,6] $\mathrm{C}_{61}$ (PCBM) (98\%), and poly(3,4-ethylenedioxythiophene): polystyrene sulphonate [PEDOT:PSS] (98\%) were purchased from Merck, Germany. 1,2-Dichlorobenzene (99\%) and isopropyl alcohol (99\%) were sourced from a different company, that is, Vetec Química Fina Ltda., Brazil.

B-CNTs were synthesized using a modified method previously reported in the literature [19]. Briefly, a mixture of ferrocene ( $2.5 \mathrm{wt} . \%)$ as the catalyst, triphenylborane (5.0 wt.\%) as the boron source, and toluene (to make $100 \mathrm{wt} . \%$ ) as the carbon source was pyrolysed at $900^{\circ} \mathrm{C}$ in a quartz reactor tube in a muffle furnace. A mixture of $10 \mathrm{wt} . \%$ hydrogen gas in argon was used as a carrier gas as well as reducing agent. N-CNTs were synthesized as reported earlier by our group [20]. Briefly, 2.5 wt. $\%$ of (4-\{[(pyridin4-yl)methylidene] amino\}phenyl)-ferrocene catalyst was dissolved in acetonitrile solvent to make $100 \mathrm{wt} . \%$ solution. This was followed by pyrolysis at $850^{\circ} \mathrm{C}$ in a quartz reactor tube in a muffle furnace. As-synthesized B- and N-CNTs were purified and functionalized by refluxing with $6 \mathrm{M}$ nitric acid for $24 \mathrm{hr}$. To enhance the CNTs dispersion properties in solvents, they were further functionalized with benzyl alcohol as illustrated in Scheme 1.

2.2. Preparation of B- and N-CNTs/P3HT: PCBM Solution. Solution for the devices was prepared using a modified method previously reported in the literature [11]. Briefly, $1.0 \mathrm{wt} . \%$ of B- or N-CNTs to the weight of P3HT was weighed and dispersed in $1.3 \mathrm{~g}$ of 1,2-dichlorobenzene and bath-sonicated by using ultrasonic cleaner model UD150SH 


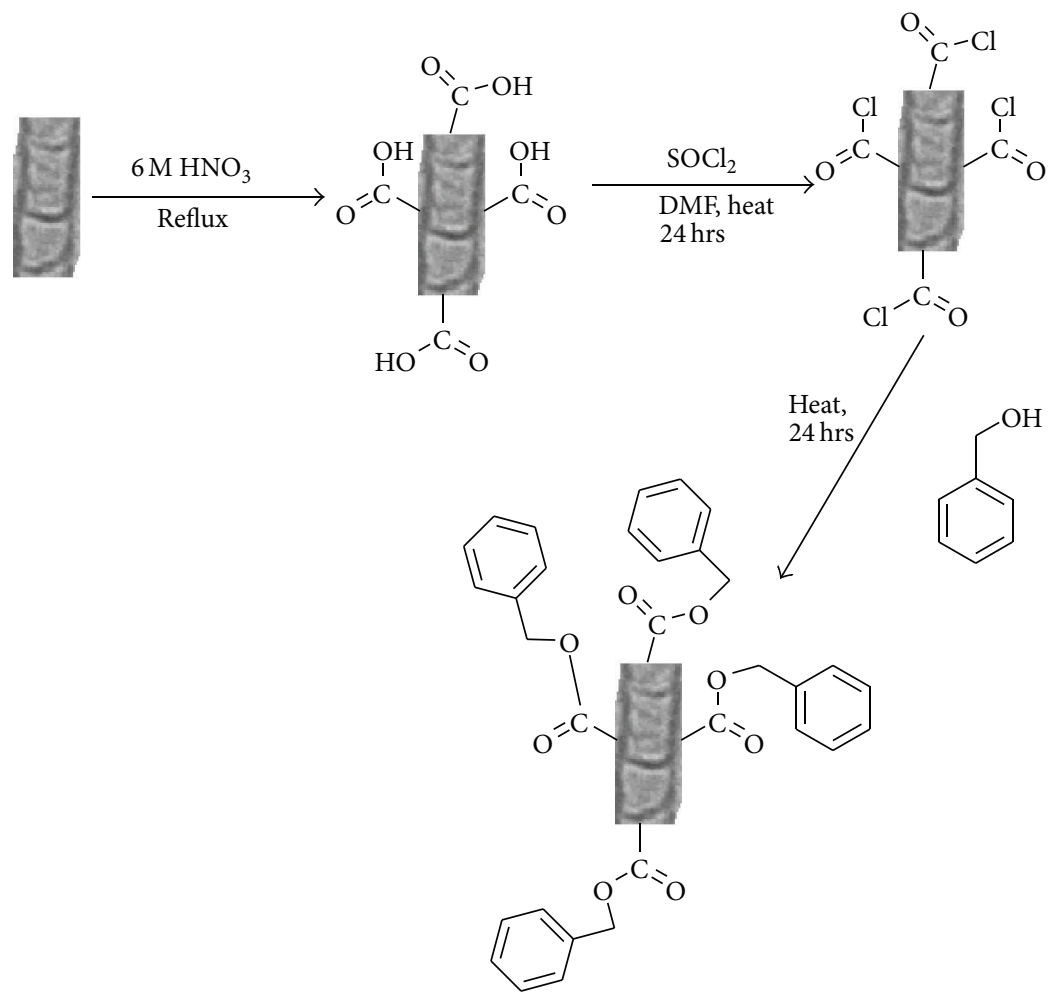

Scheme 1: Functionalization of B- and N-CNTs with benzyl alcohol via ester bond.

operating at $400 \mathrm{kHz}$ for $1 \mathrm{hr}$. To this mixture, $10 \mathrm{mg}$ of P3HT and $10 \mathrm{mg}$ of PCBM were added to the dispersion and further sonicated for $1 \mathrm{hr}$. The mixture was then transferred to a stirring plate and stirred for $12 \mathrm{hr}$ at $50^{\circ} \mathrm{C}$, in the dark. A solution of $\mathrm{P} 3 \mathrm{HT}$ : $\mathrm{PCBM}$ without $\mathrm{CNTs}$ was also prepared in a similar manner.

2.3. Device Preparation. Devices were prepared on indium tin oxide (ITO) coated substrates (Lumtec, $15 \Omega$ ). Part of the ITO was etched by putting a paste of zinc metal on the part that needed to be etched then put in a $6 \mathrm{M}$ hydrochloric acid solution. The etched substrate was cleaned by sequentially sonicating with a detergent solution, distilled water, acetone, and isopropyl alcohol, for $10 \mathrm{~min}$ in each case. Clean substrates were dried in a stream of dry nitrogen gas. A $20 \mu \mathrm{L}$ of PEDOT:PSS was spin coated on the cleaned substrates at $3500 \mathrm{rpm}$ for $50 \mathrm{~s}$ and then annealed for $10 \mathrm{~min}$ at $120^{\circ} \mathrm{C}$. A $20 \mu \mathrm{L}$ photoactive layer B- or N-CNTs/P3HT: PCBM was spin-coated at $1500 \mathrm{rpm}$ for $30 \mathrm{~s}$ and then annealed in the dark for $20 \mathrm{~min}$ at $120^{\circ} \mathrm{C}$. A thin buffer layer of lithium fluoride $(0.5 \mathrm{~nm})$ and $60 \mathrm{~nm}$ thick aluminium electrodes were vacuum-evaporated at $1.5 \times 10^{-6}$ mbars. Thin film of the photoactive layer was spin-coated from the same solution and similar conditions on a glass substrate without ITO for TAS and AFM characterization. A similar solution of P3HT:PCBM without CNTs was also prepared to make devices for comparative purposes. In all the devices, spin coating of the solutions was carried out in ambient conditions and then quickly transferred into a glove box for annealing and characterization.

2.4. Characterization Techniques. As-prepared B- or NCNTs structures were determined with transmission electron microscopy (TEM), JEOL JEM 1010 transmission electron microscope, at $200 \mathrm{kV}$. Images were captured using Megaview 3 camera and then analysed using iTEM software. Samples were dispersed in ethanol by sonication and then deposited on carbon coated copper grids. Morphology of the thin film was determined with AFM, Agilent Pico Scan 5500 microscope in a tapping mode. Images were acquired using Nanosurf Easyscan 2. For SEM, a JEOL-JSM-6360 LV operating at $20 \mathrm{kV}$ was used. Images were acquired using JSM-6360 LV software.

The elemental composition, as well as the chemical bonding environment of boron- and nitrogen-doped in the CNTs, was analysed with X-ray photoelectron spectroscopy (XPS), Thermo VG Scientific Sigma Probe instrument. The monochromatic Al K $\alpha$ X-ray source $(1486.6 \mathrm{eV})$ was focused on the sample (size $400 \mu \mathrm{m}$ ). The high resolution spectra were collected by passing energy of $20 \mathrm{eV}$ at energy step size of $0.1 \mathrm{eV}$ with flood gun turned on to eliminate surface charge.

Absorption of the P3HT : PCBM films and for those with B- or N-CNTs was determined with UV-Vis, model Hp 8452A diode array spectrometer equipped with Hp UV-Vis Chemstation software. Photoluminescence quenching of P3HT by either B- or N-CNTs was determined using a dilute solution 


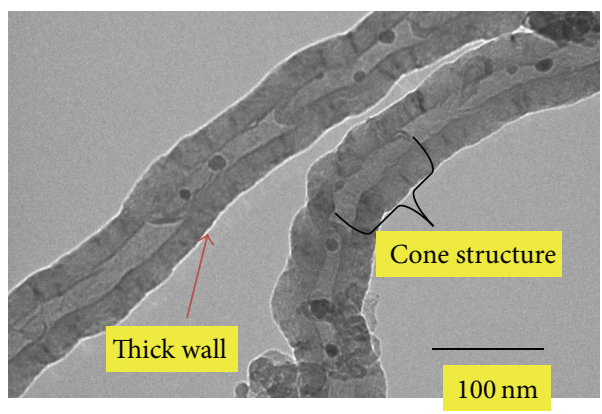

(a)

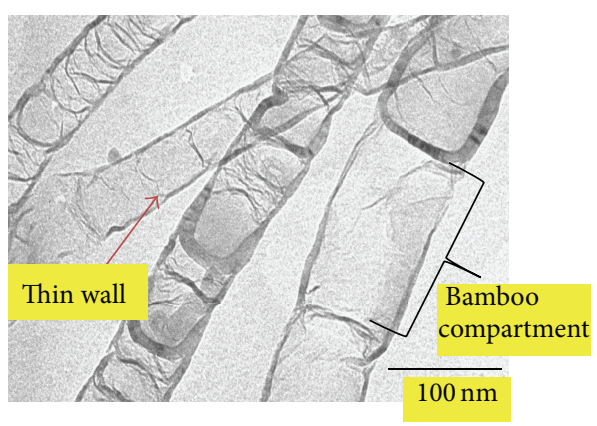

(b)

FIGURE 1: Structure of (a) B-CNTs with cone shaped structures and thick walls and (b) N-CNTs with bamboo compartments and thin walls.

of P3HT/B- or N-CNTs in 1,2 dichlorobenzene with a ISSPC1 spectrofluorometer (using Vinci software), at $440 \mathrm{~nm}$ excitation wavelength. Solution for photoluminescence was prepared as reported in the literature [21]. In brief, $20 \mathrm{mg}$ of P3HT was dissolved in 1,2-dichlorobenzene to make $100 \mathrm{~mL}$ solution. For solutions with B- or N-CNTs, $1.0 \mathrm{wt}$ \% to the weight of $\mathrm{P} 3 \mathrm{HT}$ of B- or N-CNTs was added and then bathsonicated for one hour. Necessary equivalent dilutions were made to record spectra.

Charge recombination dynamics and the yield of free charge carrier pairs that were generated in the photoactive films layer (B- or N-CNTs/P3HT : PCBM and P3HT: PCBM) were determined using microsecond to millisecond laserbased TAS following photoexcitation of the films. TAS kinetic traces were taken using a simultaneous pump and probe setup. A pulsed nitrogen laser (Photon Technology International GL-3300) was used to excite a dye laser (Photon Technology International GL-301), producing emission at $540 \mathrm{~nm}$ which was directed to the sample, and this induced electronic excitation. A quartz halogen lamp (Bentham IL1) and photodiode were used to measure the absorption characteristics of the samples at a typical probe wavelength of $950 \mathrm{~nm}$. Monochromators (Photon Technology International) were employed to refine the probe wavelength.

Hall Effect measurements were carried out using Ecopia Hall effect measurements system, model HMS 3000 equipped with HMS3000 VER 3.15.5 software in the presence of a $0.695 \mathrm{~T}$ permanent magnet. A thin film of $\mathrm{B}-$ or $\mathrm{N}$ CNTs was deposited on a glass substrate by drop-casting from 1,2-dichlorobenzene solution. Aluminium metal was thermoevaporated in van der Pauw geometry on top of the film to provide four probes contacts. Current-voltage characteristics of the devices were determined using Keithley, model 2400 source meter, with a xenon lamp illumination at $100 \mathrm{~mW} \mathrm{~cm}^{-2}$.

\section{Results and Discussion}

3.1. Structure of B- and N-CNTs. Pristine CNTs usually have tubular structures which are hollow and can be modified with the introduction of heteroatoms such as boron or nitrogen into the carbon network [22-24]. Figure 1 presents typical TEM images of the B-CNTs and N-CNTs. From the figure,
TABLE 1: Peak range for each and quantity (at.\%) of boron, nitrogen, oxygen, and carbon in B- and N-CNTs.

\begin{tabular}{lccc}
\hline Type of CNTs & Peak position $(\mathrm{eV})$ & Element & Atomic \% \\
\hline \multirow{3}{*}{ B-CNTs } & $186.0-193.5$ & B 1s & 1.5 \\
& $282.0-293.0$ & C 1s & 88.8 \\
& $528.0-537.0$ & O 1s & 9.7 \\
\hline \multirow{3}{*}{ N-CNTs } & $283.0-293.9$ & C 1s & 87.0 \\
& $396.5-407.5$ & N 1s & 4.0 \\
& $527.5-407.5$ & O ls & 9.0 \\
\hline
\end{tabular}

we observed cone shaped structures and thick walls $(\sim 15 \mathrm{~nm})$ for B-CNTs whereas N-CNTs had bamboo compartments and thin walls $(\sim 6 \mathrm{~nm})$. Formation of cone shaped structures and bamboo compartment were preliminary indictors of incorporation of boron and nitrogen heteroatoms in the hexagonal carbon network [25]. B-CNTs were also observed to have kinks and twisted compared to N-CNTs which were relatively straight. The kink and twist observed can be attributed to the size of B-C bonds which are larger than C-C bond by about $0.5 \%$ [26].

Incorporation of boron and nitrogen in the carbon network was further assessed using XPS. For B-CNTs, three peaks were identified, that is, a peak at $\sim 190 \mathrm{eV}$ assigned to $\mathrm{B} 1 \mathrm{~s}, \sim 284.5 \mathrm{eV}$ assigned to $\mathrm{C} 1 \mathrm{~s}$ from $\mathrm{sp}^{2}$ hybridised carbon, and $\sim 532.7 \mathrm{eV}$ for $\mathrm{O} 1 \mathrm{~s}$. For the N-CNTs, three peaks were also identified and assigned as follow: at $\sim 284.7 \mathrm{eV}$ for C 1s, at $\sim 401 \mathrm{eV}$ for $\mathrm{N} 1 \mathrm{~s}$, and at $\sim 531.8 \mathrm{eV}$ for $\mathrm{O}$ 1s. Table 1 illustrates the atomic $\%$ of each and peak ranges as determined by XPS.

The oxygen detected could have originated from two sources; that is, firstly, it could be introduced during acid purification and, secondly, it could be from physisorption process through oxygen-doping on the CNTs walls [27]. To determine the elemental composition as well as the chemical bonding environment of boron and nitrogen in $\mathrm{B}$ - and $\mathrm{N}$ $\mathrm{CNTs}, \mathrm{B} 1 \mathrm{~s}$ and $\mathrm{N}$ 1s peaks were deconvoluted. The $\mathrm{B} 1 \mathrm{~s}$ peak at 186-193.5 eV was deconvoluted into 4 peaks (Figure 2). Lower peaks (186-189 eV) are associated with B-C bonding while the ones at high energy levels (190-194 eV) are associated with oxidised species of boron and correspond to $\mathrm{BC}_{2} \mathrm{O}, \mathrm{BCO}_{2}$, and $\mathrm{B}_{2} \mathrm{O}_{3}$ [28]. 


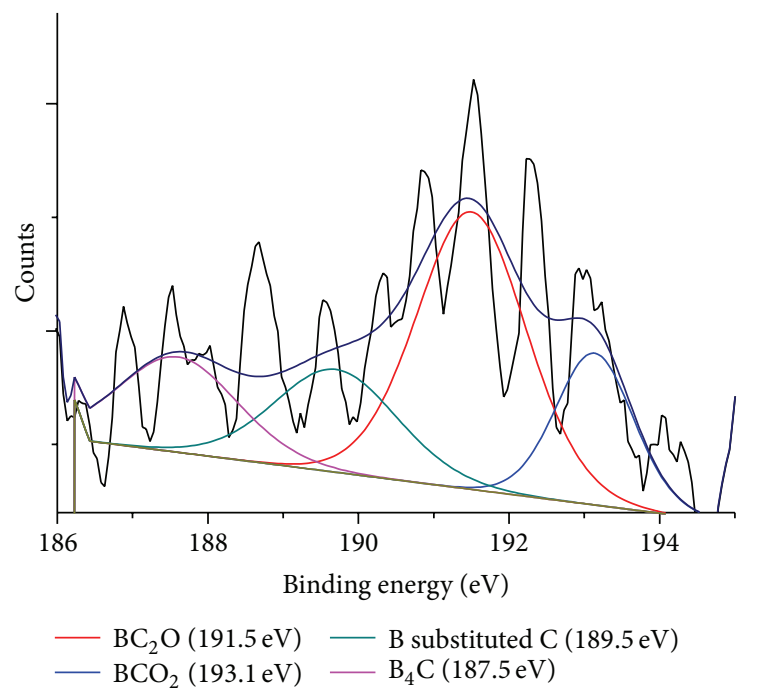

Figure 2: Deconvoluted B 1s peaks showing the bonding environment of boron in B-CNTs.

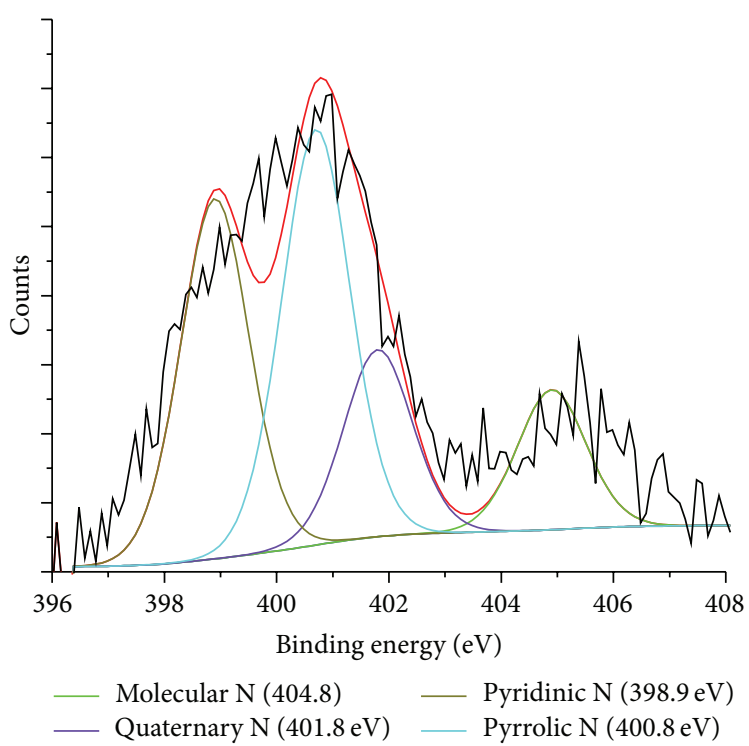

FIgURE 3: The four peaks of $\mathrm{N} 1 \mathrm{~s}$ after deconvolution.

From Figure 2, substituted boron peak was the smallest indicating that very little boron was incorporated into the hexagonal network of carbon. B-CNTs with low boron concentration exhibit metallic character since insertion of boron in hexagonal carbon network results in large number of acceptors near the Fermi level [28]. Effect of this in the photoactive layer of OSC will be discussed later in Section 3.3.

The $\mathrm{N}$ 1s peak at $396.5-407.5 \mathrm{eV}$ was also deconvoluted into 4 peaks (Figure 3 ) which corresponds to the 4 different bonding environments of nitrogen in a hexagonal carbon network. From Figure 3, the highest peak obtained was that of pyrrolic nitrogen, followed by pyridinic and quaternary, and lastly the smallest represented the molecular nitrogen. The carbon-nitrogen ( $\mathrm{C}-\mathrm{N})$ bonds in quaternary or pyrrolic environs provide delocalised electrons into the $\mathrm{sp}^{2}$ hybridized
TABLE 2: Hall effects measurements and mobility of thin film of Band N-CNTs.

\begin{tabular}{lccc}
\hline $\begin{array}{l}\text { Type of } \\
\text { CNTs }\end{array}$ & $\begin{array}{c}\text { Bulk concentration } \\
\left(\mathrm{cm}^{-3}\right)\end{array}$ & $\begin{array}{c}\text { Sheet concentration } \\
\left(\mathrm{cm}^{-2}\right)\end{array}$ & $\begin{array}{c}\text { Mobility } \\
\left(\mathrm{cm}^{2} \mathrm{~V}^{-1} \mathrm{~s}^{-1}\right)\end{array}$ \\
\hline N-CNTs & $-1.962 \times 10^{21}$ & $-4.905 \times 10^{16}$ & $2.025 \times 10^{-1}$ \\
B-CNTs & $1.592 \times 10^{19}$ & $3.980 \times 10^{14}$ & 1.514 \\
\hline
\end{tabular}

carbon lattice. This induces sharp localised states above the Fermi level due to extra electrons, and this results in the NCNTs behaving like n-type semiconductor or donor states. However, pyridinic type, where nitrogen is coordinated by two carbon atoms, induces localised states below the Fermi level. These make N-CNTs that were semiconducting to show metallic (p-type) behaviour depending on the level of doping [29].

Effect of this on the performance in OSCs will be discussed later in Section 3.3. B- or N-CNTs were mixed with polymer $\mathrm{P} 3 \mathrm{HT}$ to form nanocomposites that were eventually mixed with PCBM to form part of the photoactive layer in OSC.

Behaviour of B-CNTs as p-type and N-CNTs as ntype semiconductors was further supported by Hall effect measurements (Table 2). The negative value for bulk concentration in N-CNTs and positive value in B-CNTs were an indicator that they were behaving as n-type and p-type, respectively, semiconductors. Baumgartner et al. [30] studied a film of MWCNTs using Hall effect measurements and, in their findings, a positive Hall coefficient value was obtained and they concluded that the film was predominantly a hole conductor (p-type).

3.2. Effect of B- or N-CNTs on the Spectroscopic Properties of the P3HT:CNTs Blends. Photoluminescence of the nanocomposite (Figure 4) was obtained from a solution of $\mathrm{P} 3 \mathrm{HT} / \mathrm{B}$ - or N-CNTs in 1,2-dichlorobenzene before PCBM was added. From the figure, we observed $\sim 50 \%$ quenching of the emission spectra with the inclusion of N-CNTs. This was an indication of charge transfer between N-CNTs and P3HT. We attribute this quenching to the position of P3HT LUMO $(-3.2 \mathrm{eV})$ and work function of N-CNTs $(-4.2 \mathrm{eV})$ which are close to each other [11]. This makes it energetically favourable for electrons transfer from P3HT LUMO to NCNTs. Our observations differ with those of Lee et al. [12] who reported insignificant quenching for a solution of $\mathrm{P} 3 \mathrm{HT}$ and N-CNTs. They attributed this to energy barriers between semiconductor (P3HT) and conductor (N-CNTs). However, $\mathrm{B}-\mathrm{CNTs}$ spectrum was almost a replica to that of $\mathrm{P} 3 \mathrm{HT}$. The possible reason for this was that B-CNTs do not accept electrons from the P3HT due to the mismatch between the work function of B-CNTs $(-5.2 \mathrm{eV})$ and the LUMO of P3HT $(-3.2 \mathrm{eV})$; hence, quenching was not possible.

Absorbance of the nanocomposite was measured after mixing P3HT/B- or N-CNTs with PCBM and then spincoating thin films on a glass substrate and annealing at $120^{\circ} \mathrm{C}$ for $10 \mathrm{~min}$ (Figure 5).

From Figure 5, we noted a red shift for the absorbance of P3HT when B- or N-CNTs (from $500.5 \mathrm{~nm}$ to $507.9 \mathrm{~nm}$ and 
TABle 3: Photovoltaic characteristics of the devices.

\begin{tabular}{lcccc}
\hline OSC & $V_{\mathrm{OC}}(\mathrm{V})$ & $J_{\mathrm{SC}}\left(\mathrm{mA} / \mathrm{cm}^{2}\right)$ & $\mathrm{FF}(\%)$ & $\eta(\%)$ \\
\hline P3HT $:$ PCBM & $0.557 \pm 1.2$ & $7.114 \pm 0.8$ & $54.2 \pm 1$ & $3.15 \pm 0.5$ \\
P3HT/B-CNTs : PCBM & $0.277 \pm 0.7$ & $6.452 \pm 1.5$ & $30.2 \pm 0.5$ & $0.54 \pm 1$ \\
P3HT/N-CNTs : PCBM & $0.302 \pm 2$ & $6.863 \pm 0.5$ & $28.1 \pm 0.9$ & $0.58 \pm 0.2$ \\
\hline
\end{tabular}

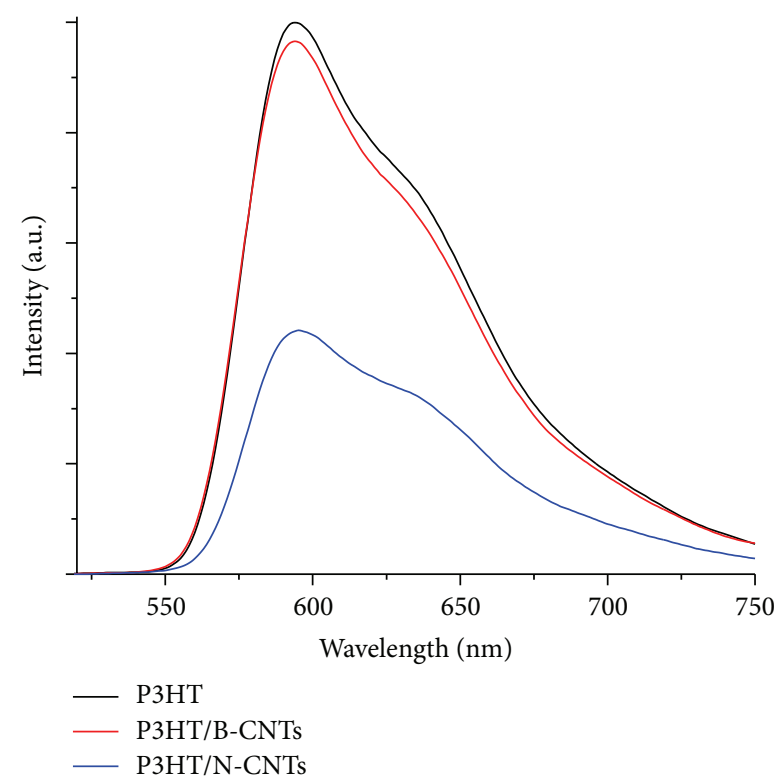

FIgURE 4: Photoluminescence spectra for pristine P3HT (black curve), overlapped by P3HT/B-CNTs (red curve) and quenching by $\mathrm{P} 3 \mathrm{HT} / \mathrm{N}-\mathrm{CNTs}$ (blue curve).

$514.3 \mathrm{~nm}$ for B-CNTs and N-CNTs), respectively, were added to the polymer. Similar observations were made by Karim [31], who attributed this to enhanced ground interaction between CNTs and the polymer. Due to this interaction, we expected CNTs to create a good percolation pathway for the photo-generated charge carriers and eventual efficient collection at the electrodes. A maximum absorption $\left(\lambda_{\max }\right)$ of $500.5 \mathrm{~nm}, 507.9 \mathrm{~nm}$, and $514.3 \mathrm{~nm}$ for P3HT, P3HT/B-CNTs, and $\mathrm{P} 3 \mathrm{HT} / \mathrm{N}-\mathrm{CNT}$ s was observed, respectively. The slight red shift of $\lambda_{\max }$ for the films with doped CNTs was attributed to polymer wrapping on the CNTs surfaces which increased conjugation length as a result of $\pi-\pi$ interactions [32]. The $\lambda_{\max }$ observed for thin film was more red-shifted compared to that of a solution of P3HT in 1,2-dichlorobenzene (not shown here) which was $442 \mathrm{~nm}$. This red shift can be due to enhanced polymer structure ordering by annealing [33]. Additionally, annealing increases $\pi-\pi$ overlap in the polymer chains and causes phase segregation between the donor polymer and acceptor PCBM which increases $\lambda_{\max }$ of the polymer [34].

3.3. Photovoltaic Properties. Bulk heterojunction organic solar cells were produced in a sandwich type device structure consisting of different layers of materials (Figure 6). The photoactive layer was composed of $\mathrm{P} 3 \mathrm{HT} / \mathrm{B}-\mathrm{CNT} / \mathrm{PCBM}$ or P3HT/N-CNT/PCBM.

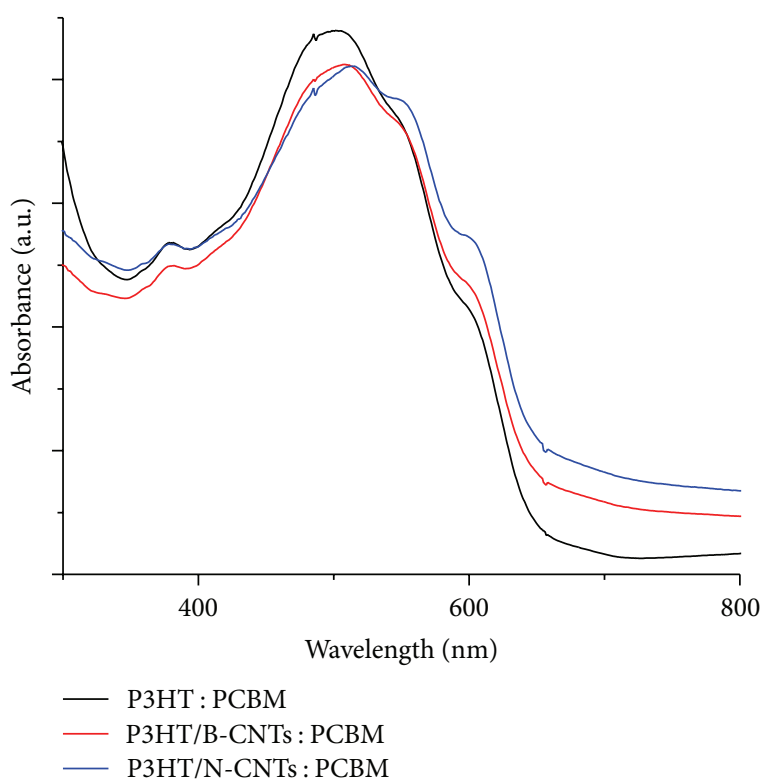

FIgURE 5: UV-Vis absorbance of thin films black pristine P3HT, red P3HT/B-CNTs, and blue P3HT/N-CNTs; all the films had PCBM.

The current-voltage $(J-V)$ curves given in Figure 7 are typical representatives of the OSC diodes under investigation. According to the cell parameters provided in Table 3, the performance of the devices did not improve as expected after blending the photoactive layer with B- or N-CNTs.

The device without doped CNTs had an efficiency of $2.15 \%$ while the ones with B-CNTs and N-CNTs had $0.54 \%$ and $0.58 \%$, respectively. Despite the fact that the two types of CNTs have different electrical properties (i.e., the N-CNTs behaving like n-type and B-CNTs as p-type semiconductors), both have exhibited similar behaviour in the devices. By intermixing the P3HT donor, PCBM electron acceptor with either B- or N-CNTs was expected to improve the efficiency of charge separation at the D-A interfaces. This was to take place in the photoactive medium by a way of enhanced charge transfer as a result of high mobility in doped CNTs [35]. However, the samples with doped CNTs exhibited drastic reduction in the values of the $V_{\mathrm{OC}}$ and FF which might be attributed to high recombination in the devices. Similar behaviour was manifested in both types of doped CNTs which could also be associated with the metallic character induced by low level of boron doping in B-CNTs and high level of pyridinic nitrogen in N-CNTs. In all the devices, it was anticipated to have almost the same $V_{\text {OC }}$ as it mainly depends on the difference between the HOMO level of the donor and the LUMO level of the acceptor $[36,37]$. The observed low $V_{\text {OC }}$ in the solar cells with doped CNTs can be attributed 


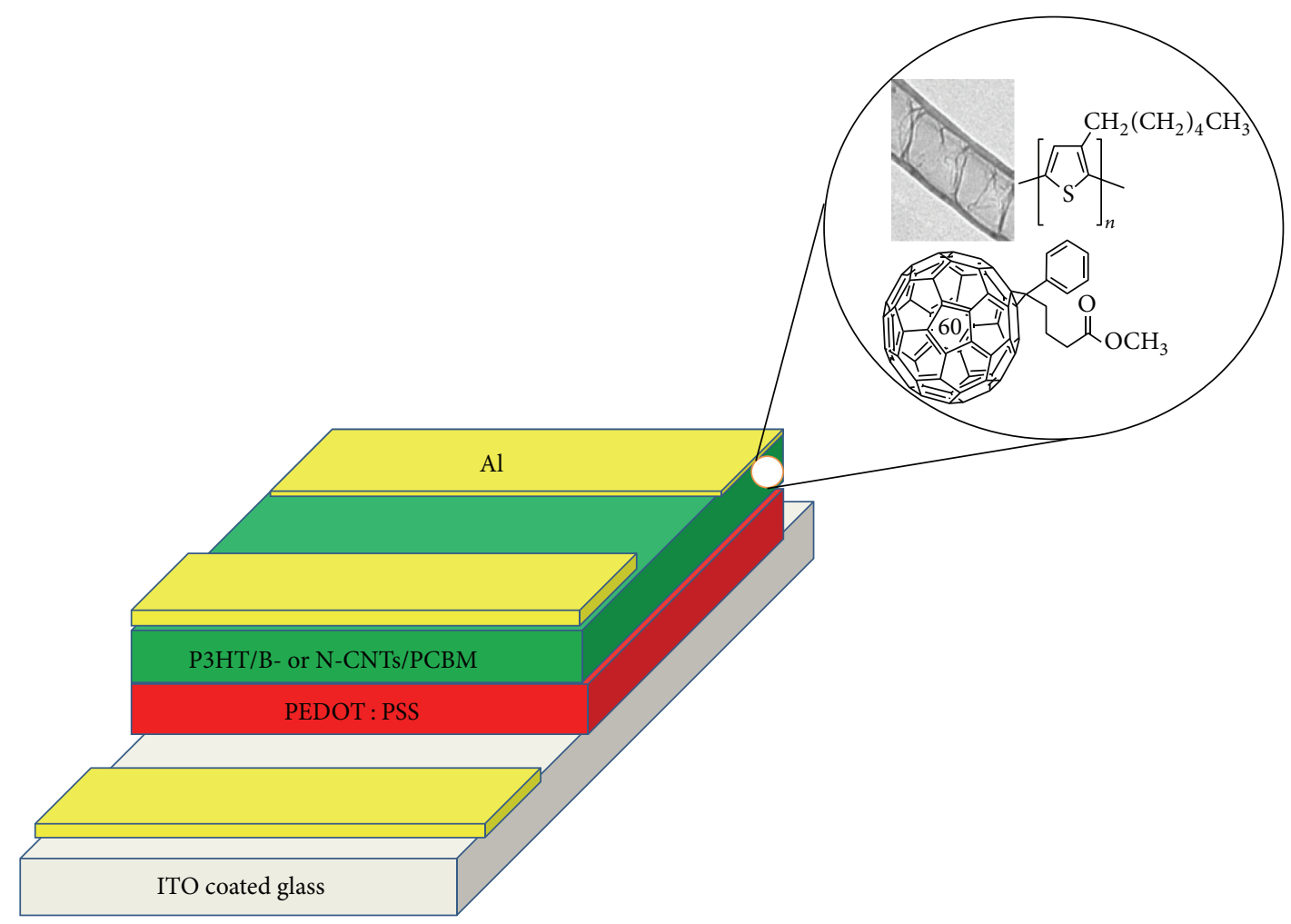

FIgURE 6: Schematic diagram of the device.

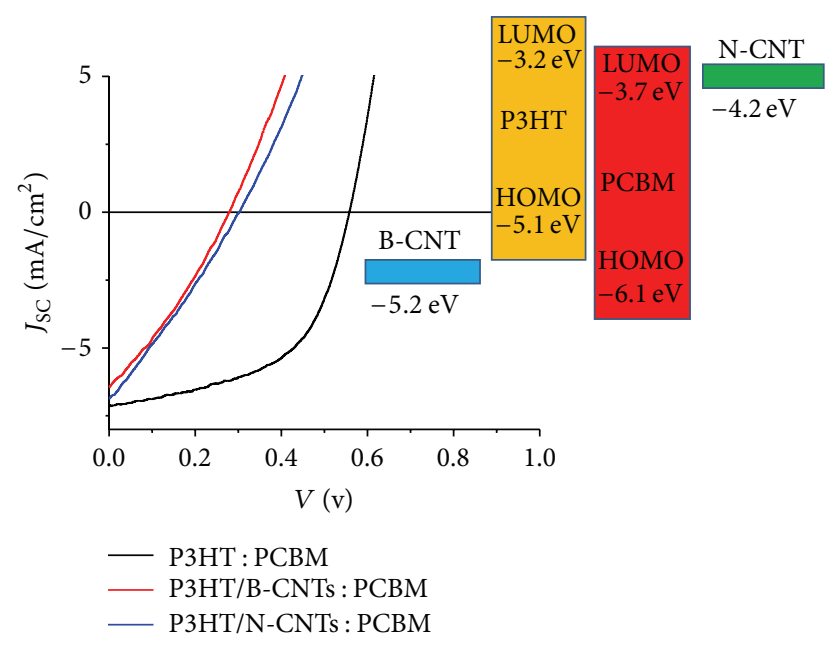

FIGURE 7: $I-V$ curves of devices with and without doped CNTs and the energy band diagram showing the positions of HOMO and LUMO of donor and acceptor as well as work functions of doped CNTs.

to the recombination processes and low shunt resistances (43.4, $51.7 \Omega$ for devices with B-CNTs and N-CNTs, resp., as compared to $416.1 \Omega$ for the device without CNTs) due to possible short circuits and leakage current caused by the presence of out-protruding CNTs in the photoactive layer. Derbal-Habak et al. [15] reported that the presence of metallic CNTs in the photoactive layer favours recombination of free charge carriers. Additionally, Holt et al. [38] used time-resolved microwave conductivity to show that metallic SWCNTs in P3HT blend were unfavourable to photovoltaic performance.

According to the results given in Table 3, the devices had similar $J_{S C}$ values which are known to depend on device quantum efficiency (QE). The $\mathrm{QE}$ of a device is proportional to light absorption by the photoactive layer followed by excitons dissociation at the D-A interfaces as well as the efficiency of charge collection. The results in Table 3 suggest that the collection of the current from all the devices are almost the same but differ significantly in the values of the open circuit voltages which is responsible for the variations in the power conversion efficiencies. These results indicate that the low $V_{\mathrm{OC}}$ mainly comes from high leakage current in the devices due to the existence of doped CNTs in the sample. High leakage current often results in low shunt resistance which severely affects the value of the open circuit voltage. However, Lee and coworkers $[11,12]$ have reported impressive power conversion efficiency of $5.29 \%$ and $4.11 \%$ using N-CNT and B-CNTs, respectively. The difference in device performances is due to the fact that our samples were prepared in ambient environment and the doping level in the CNTs used was different.

3.4. Morphology of the Films. Morphology and size of photoactive layer films of the devices were analysed using AFM and SEM. Figure 8 shows AFM images of these films. From the images, it was observed that films with N-CNTs were 

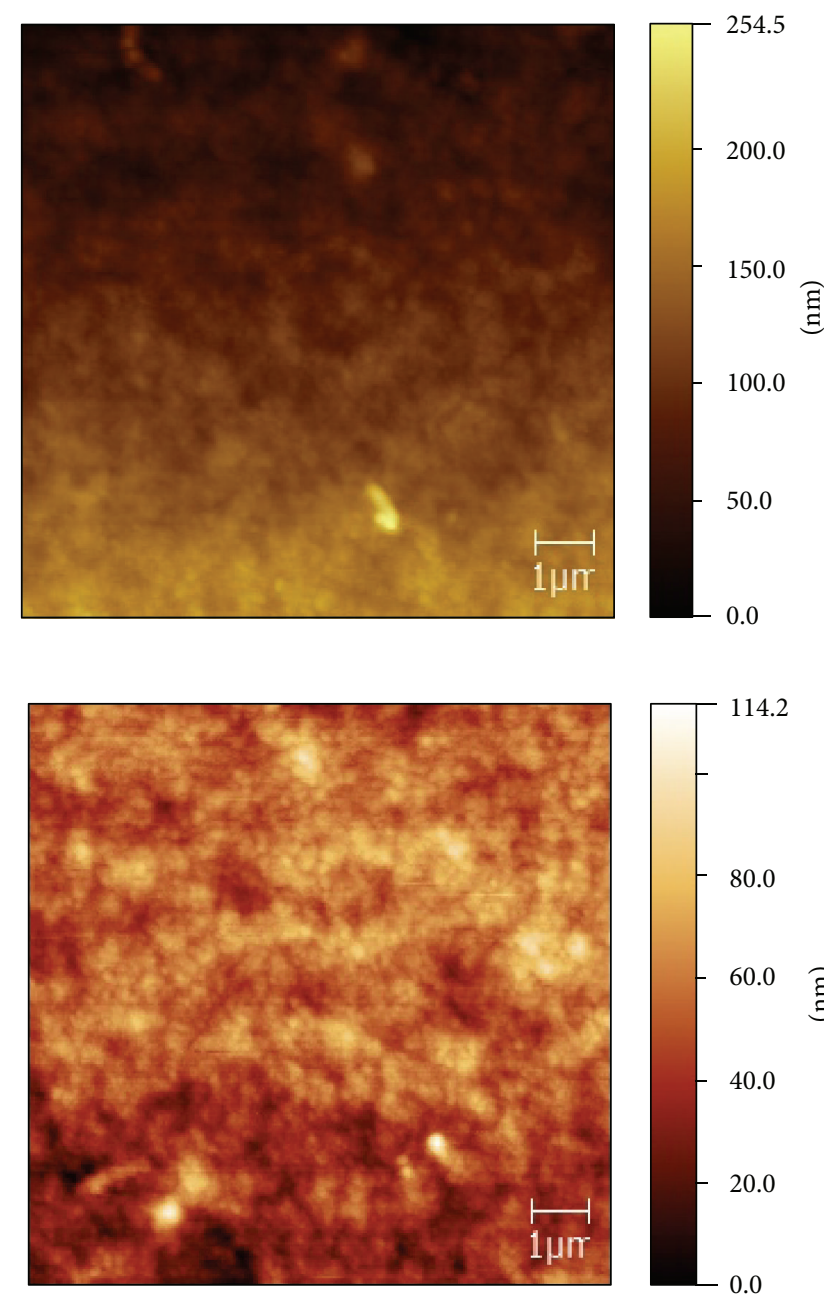

(a)
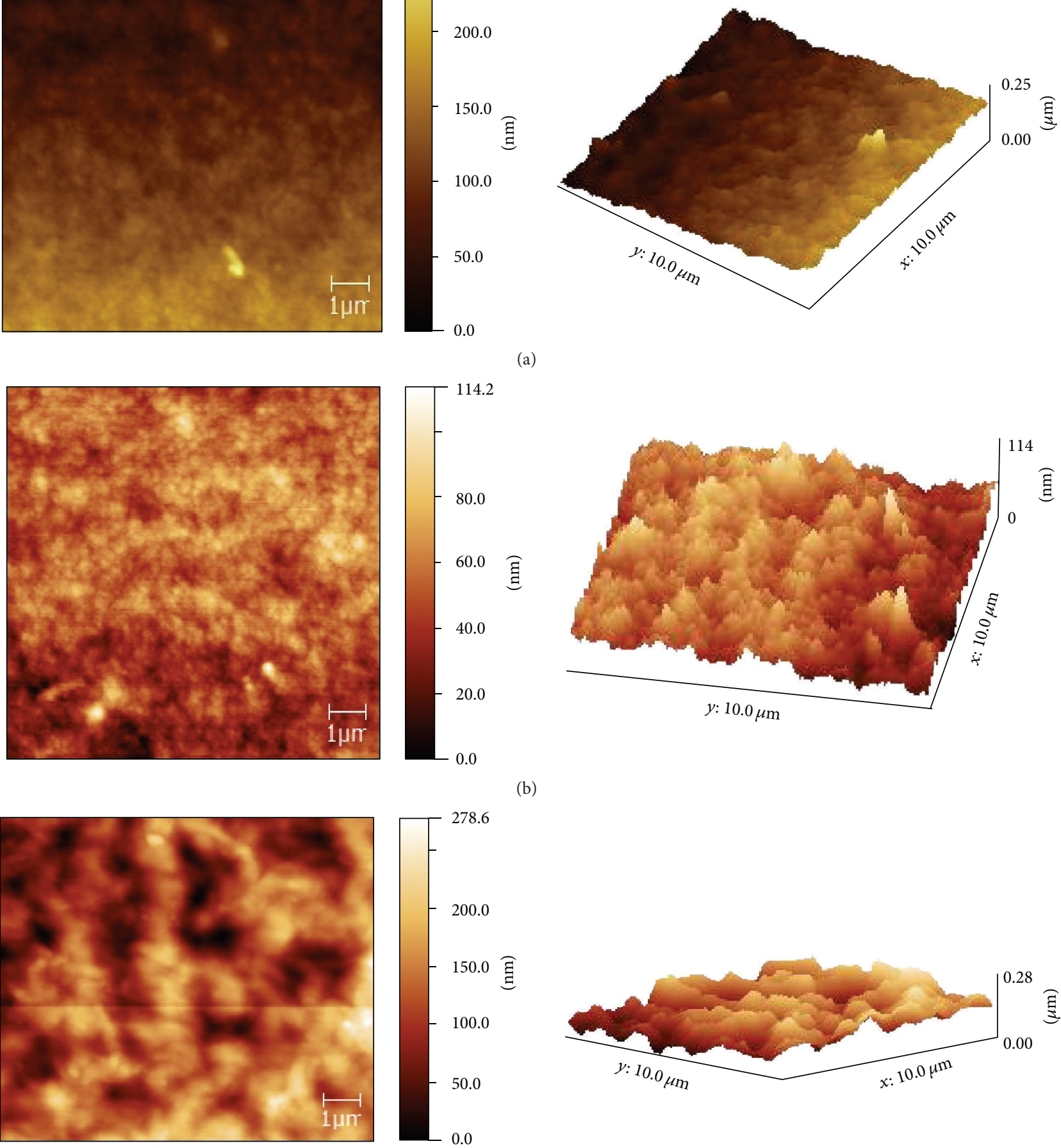

(b)

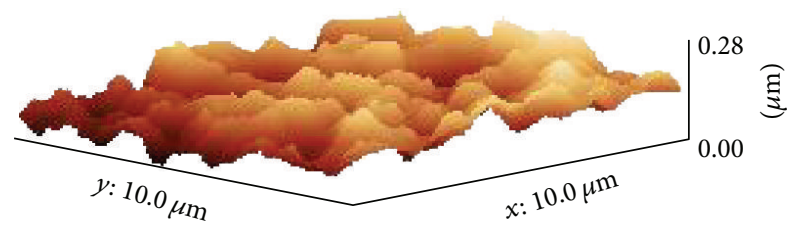

(c)

Figure 8: AFM film images of (a) P3HT: PCBM, (b) $114.2 \mathrm{~nm}$ thick film of P3HT/N-CNTs: PCBM, and (c) $278.6 \mathrm{~nm}$ thick film of P3HT/NCNTs : PCBM.

rougher compared to the one without doped-CNTs. This roughness decreased as the film thickness increased, that is, from $114.2 \mathrm{~nm}$ to $278.2 \mathrm{~nm}$. Similar observations were made for $257 \mathrm{~nm}$ and $160 \mathrm{~nm}$ thick films with B-CNTs. However, specific RMS roughness values were found to be dependent on film thickness that is $46.8,42.1$, and $13.9 \mathrm{~nm}$ for 278.6 , 254.5 , and $114.2 \mathrm{~nm}$ thick films, respectively. The average size of the photoactive layer was $250 \mathrm{~nm}$. We observed sharp pointed filaments protruding on the surface of the films with doped-CNTS. These filaments could be the cause of 


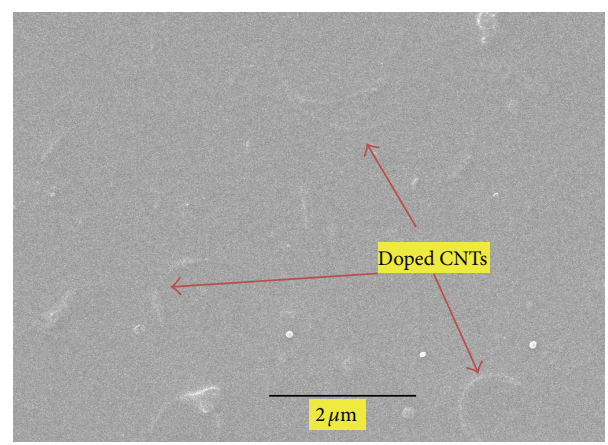

FIgure 9: SEM image showing dispersion of doped CNTs. The length of the doped CNTs is in microns scale.

short circuiting of these devices. This has also been suggested by Berson et al. [5] who attributed reduction in $V_{\mathrm{OC}}$ and $\mathrm{FF}$ in their devices P3HT/CNT/PCBM to the formation of filamentary electrical short circuiting which was as a result of CNTs extending across the photoactive layer.

The SEM image in Figure 9 shows that the doped CNTs were well dispersed in the film; therefore, we ruled out bundling of CNTs in these devices. Hence, we attribute the good dispersion to covalent functionalization of our doped CNTs with benzyl alcohol via ester groups. This has been reported by other authors where the covalent functionalization of CNTs with ester groups promotes dispersion in the polymer matrix [15].

From Figure 9, the size of the doped CNTs was bigger compared to the thickness of the film $\sim 250 \mathrm{~nm}$. Hence, there is a possibility that the doped-CNTs were extending across the photoactive layer.

3.5. Recombination Dynamics in the Film Blends. Although intermixing of polymer donor and fullerene acceptor results in significant enhancement of photo-induced charge generation, it can also increase the interfacial area available for bimolecular recombination. Transient absorption spectroscopy (TAS) was used to study recombination dynamics in P3HT : PCBM, P3HT/B- or N-CNTs films blend. TAS was used to provide information on the yield of photo-generated charges (polarons). This was achieved by monitoring optical absorption which directly relates to the yield of photogenerated charges [39]. Figure 10 shows TAS signal for the blend films at $540 \mathrm{~nm}$ pump wavelength and $950 \mathrm{~nm}$ probe wavelength at 1s time delay. The probe wavelength was set at $950 \mathrm{~nm}$ in order to correspond with transient absorption of $\mathrm{P} 3 \mathrm{HT}$ positive polarons $\left(\mathrm{P}_{3} \mathrm{HT}^{+}\right)$. Additionally, low intensity excitation was employed to ensure photo-generated charge carriers were comparable with those generated under solar illumination.

We observed the films transient signal decay corresponding to power law decay ( $\Delta \mathrm{OD} \alpha t^{-\alpha}$ ) suggesting traplimited recombination extending to millisecond time scale $[39,40]$. This long-lived power law decay is a characteristic of bimolecular charge recombination of dissociated charged species [41]. TAS excitation was undertaken in a nitrogen atmosphere (films were put in a culvert and then filled with

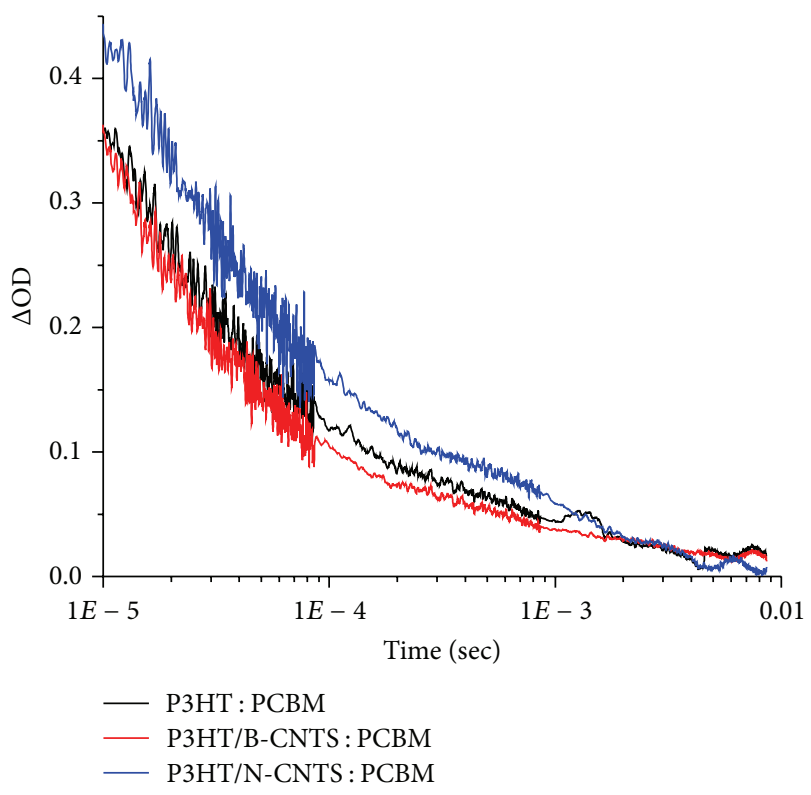

Figure 10: The transient absorption decay kinetics of a P3HT:PCBM (1:1) blend film and a similar blend containing 1.0 wt.\% of either B- or N-CNTs obtained as a function of laser excitation density with a pump wavelength of $540 \mathrm{~nm}$ and a probe wavelength of $950 \mathrm{~nm}$.

nitrogen gas). To rule out the formation of triplet state, the same experiment was also done under oxygen atmosphere and it was observed that the signal was not quenched. This has also been observed by Ohkita et al. [42].

Despite the fact that the blend with N-CNTs had the highest percent of photo-generated charge carriers which also had the longest life time (average time a free charge carrier lives before recombining nongeminate), this did not result into a good photovoltaic output. We anticipated good efficiency from this device due to high yield of long-lived dissociated polarons. The TAS results of high yield of photogenerated free charge carriers for P3HT/N-CNTs: PCBM film correlate well with photoluminescence results, where excitons quenching was observed and this is an indication that $\mathrm{N}$-CNTs provided extra excitons dissociation sites. The TAS results observed lead us to a conclusion that B- and NCNTs in this study were acting as generated charge carriers traps which encouraged bimolecular recombination instead of acting as pathway to the electrodes. The possible reason for this can be due to the metallic nature of the doped-CNTs used as a result of low substitutional boron concentration in B-CNTs and high percentage of pyridinic nitrogen in $\mathrm{N}$-CNTs. Additionally, the length of doped CNTs (10-20 microns) as compared to the thickness of photoactive film $(\sim 250 \mathrm{~nm})$ encouraged shunting by providing alternative path for electrons. This caused energy loss and a decrease of $V_{\mathrm{OC}}$ of the devices. Other authors, such as Liu et al. [43], have analysed intensity dependent photocurrents in P3HT/SWCNTs: PCBM and attributed the poor performance of their device to the bimolecular recombination which was due to presence of metallic SWCNTs. Hence, 
metallic CNTs do encourage bimolecular recombination and this can be the major reason for efficiency deterioration for devices with CNTs.

\section{Conclusion}

The OSC devices with B- or N-CNTs, in the photoactive layers, were successfully fabricated. The devices recorded low cell efficiency compared to a standard P3HT : PCBM device. The devices behaved in a similar manner despite the fact that $\mathrm{B}$ - and $\mathrm{N}$-doping made properties of photoactive layer different. The doped-CNTs were metallic in nature as a result of low concentration of substitutional boron in B-CNTs and pyridinic-nitrogen species in N-CNTs. Hence, this is one of the main reasons for similar behaviour within the devices. Hence, from the findings, it is important to have a very controlled heteroatom doping in CNTs. In the case of NCNTs, one should strive to eliminate unwanted species of nitrogen, that is, pyridinic nitrogen, whilst in B-CNTs one should increase the amount of substitutional boron. Also, the length of B- or N-CNTs was estimated to be between 10 and 20 microns, and thus some extended across and even protruded on both sides of the photoactive layer. The length of CNTs to be incorporated should be of the right size to improve their implementation in the photoactive layer of OSCs.

\section{Conflict of Interests}

The authors declare that there is no conflict of interests regarding the publication of this paper.

\section{Acknowledgments}

The authors thank Nanotechnology and Solar cell Laboratory, Chemistry Institute, University of Campinas, where the major part of this work was undertaken through the courtesy of Professor Dr. Ana Flavia, Brazilian Nanotechnology National Laboratory (LNNano) for the XPS facility (proposal, XPS-17582), the University of KwaZulu-Natal (UKZN), the National Research Foundation (NRF), and the India, Brazil, and South Africa (IBSA) energy project for financial assistance. G. Keru also thanks the UKZN College of Agriculture, Engineering and Science for award of a postgraduate bursary.

\section{References}

[1] C. M. Proctor, M. Kuik, and T.-Q. Nguyen, "Charge carrier recombination in organic solar cells," Progress in Polymer Science, vol. 38, no. 12, pp. 1941-1960, 2013.

[2] E. A. A. Arbab, B. Taleatu, and G. T. Mola, "Environmental stability of PTB7:PCBM bulk heterojunction solar cell," Journal of Modern Optics, vol. 61, no. 21, pp. 1749-1753, 2014.

[3] G. Keru, P. G. Ndungu, and V. O. Nyamori, "A review on carbon nanotube/polymer composites for organic solar cells," International Journal of Energy Research, vol. 38, no. 13, pp. 1635-1653, 2014.

[4] G. H. Jun, S. H. Jin, S. H. Park, S. Jeon, and S. H. Hong, "Highly dispersed carbon nanotubes in organic media for polymer: fullerene photovoltaic devices," Carbon, vol. 50, no. 1, pp. 4046, 2012.

[5] S. Berson, R. de Bettignies, S. Bailly, S. Guillerez, and B. Jousselme, "Elaboration of P3HT/CNT/PCBM composites for organic photovoltaic cells," Advanced Functional Materials, vol. 17, no. 16, pp. 3363-3370, 2007.

[6] C. Liu, C. Yi, K. Wang et al., "Single-junction polymer solar cells with over $10 \%$ efficiency by a novel two-dimensional donor-acceptor conjugated copolymer," ACS Applied Materials \& Interfaces, vol. 7, no. 8, pp. 4928-4935, 2015.

[7] J.-D. Chen, C. Cui, Y.-Q. Li et al., "Single-junction polymer solar cells exceeding $10 \%$ power conversion efficiency," Advanced Materials, vol. 27, no. 6, pp. 1035-1041, 2015.

[8] D. Baran, S. Erten-Ela, A. Kratzer, T. Ameri, C. J. Brabec, and A. Hirsch, "Facile synthesis and photovoltaic applications of a new alkylated bismethano fullerene as electron acceptor for high open circuit voltage solar cells," RSC Advances, vol. 5, no. 79, pp. 64724-64730, 2015.

[9] O. Pachoumi, C. Li, Y. Vaynzof, K. K. Banger, and H. Sirringhaus, "Improved performance and stability of inverted organic solar cells with sol-gel processed, amorphous mixed metal oxide electron extraction layers comprising alkaline earth metals," Advanced Energy Materials, vol. 3, no. 11, pp. 1428-1436, 2013.

[10] B. Ratier, J.-M. Nunzi, M. Aldissi, T. M. Kraft, and E. Buncel, "Organic solar cell materials and active layer designsimprovements with carbon nanotubes: a review," Polymer International, vol. 61, no. 3, pp. 342-354, 2012.

[11] J. M. Lee, J. S. Park, S. H. Lee, H. Kim, S. Yoo, and S. O. Kim, "Selective electron-or hole-transport enhancement in bulkheterojunction organic solar cells with $\mathrm{N}$-or B-doped carbon nanotubes," Advanced Materials, vol. 23, no. 5, pp. 629-633, 2011.

[12] J. M. Lee, B.-H. Kwon, H. I. Park et al., "Exciton dissociation and charge-transport enhancement in organic solar cells with quantum-dot/N-doped CNT hybrid nanomaterials," Advanced Materials, vol. 25, no. 14, pp. 2011-2017, 2013.

[13] S. Chaudhary, H. Lu, A. M. Müller, C. J. Bardeen, and M. Ozkan, "Hierarchical placement and associated optoelectronic impact of carbon nanotubes in polymer-fullerene solar cells," Nano Letters, vol. 7, no. 7, pp. 1973-1979, 2007.

[14] S. H. Lee, J. S. Park, B. K. Lim et al., "Highly entangled carbon nanotube scaffolds by self-organized aqueous droplets," Soft Matter, vol. 5, no. 12, pp. 2343-2346, 2009.

[15] H. Derbal-Habak, C. Bergeret, J. Cousseau, and J. M. Nunzi, "Improving the current density $J_{s c}$ of organic solar cells P3HT:PCBM by structuring the photoactive layer with functionalized SWCNTs," Solar Energy Materials and Solar Cells, vol. 95, supplement 1, pp. S53-S56, 2011.

[16] M. M. Stylianakis and E. Kymakis, "Efficiency enhancement of organic photovoltaics by addition of carbon nanotubes into both active and hole transport layer," Applied Physics Letters, vol. 100, no. 9, Article ID 093301, 2012.

[17] I. Khatri, S. Adhikari, H. R. Aryal, T. Soga, T. Jimbo, and M. Umeno, "Improving photovoltaic properties by incorporating both single walled carbon nanotubes and functionalized multiwalled carbon nanotubes," Applied Physics Letters, vol. 94, no. 9, Article ID 093509, 2009.

[18] B. K. Kuila, K. Park, and L. Dai, "Soluble P3HT-grafted carbon nanotubes: synthesis and photovoltaic application," Macromolecules, vol. 43, no. 16, pp. 6699-6705, 2010.

[19] S. Wang, L. Zhang, Z. Xia et al., "BCN graphene as efficient metal-free electrocatalyst for the oxygen reduction reaction," 
Angewandte Chemie-International Edition, vol. 51, no. 17, pp. 4209-4212, 2012.

[20] G. Keru, P. G. Ndungu, and V. O. Nyamori, "Nitrogen-doped carbon nanotubes synthesised by pyrolysis of (4-[(pyridine-4yl)methylidene] aminophenyl)ferrocene," Journal of Nanomaterials, vol. 2013, Article ID 750318, 7 pages, 2013.

[21] P. J. Goutam, D. K. Singh, P. K. Giri, and P. K. Iyer, "Enhancing the photostability of poly(3-hexylthiophene) by preparing composites with multiwalled carbon nanotubes," The Journal of Physical Chemistry B, vol. 115, no. 5, pp. 919-924, 2011.

[22] E. N. Nxumalo and N. J. Coville, "Nitrogen doped carbon nanotubes from organometallic compounds: a review," Materials, vol. 3, no. 3, pp. 2141-2171, 2010.

[23] Y. Chen, J. Wang, H. Liu et al., "Nitrogen doping effects on carbon nanotubes and the origin of the enhanced electrocatalytic activity of supported pt for proton-exchange membrane fuel cells," The Journal of Physical Chemistry C, vol. 115, no. 9, pp. 3769-3776, 2011.

[24] Q. Jiang, L. Qian, J. Yi, X. Zhu, and Y. Zhao, "Effects of borondoping on the morphology and magnetic property of carbon nanotubes," Frontiers of Materials Science in China, vol. 1, no. 4, pp. 379-382, 2007.

[25] G. Keru, P. G. Ndungu, and V. O. Nyamori, "Effect of boron concentration on physicochemical properties of boron-doped carbon nanotubes," Materials Chemistry and Physics, vol. 153, pp. 323-332, 2015.

[26] L. Yang, S. Jiang, Y. Zhao et al., "Boron-doped carbon nanotubes as metal-free electrocatalysts for the oxygen reduction reaction," Angewandte Chemie-International Edition, vol. 50, no. 31, pp. 7132-7135, 2011.

[27] F. H. Monteiro, D. G. Larrude, M. E. H. Maia da Costa, L. A. Terrazos, R. B. Capaz, and F. L. Freire, "Production and characterization of boron-doped single wall carbon nanotubes," The Journal of Physical Chemistry C, vol. 116, no. 5, pp. 32813285, 2012.

[28] S. C. Lyu, J. H. Han, K. W. Shin, and J. H. Sok, "Synthesis of boron-doped double-walled carbon nanotubes by the catalytic decomposition of tetrahydrofuran and triisopropyl borate," Carbon, vol. 49, no. 5, pp. 1532-1541, 2011.

[29] M. Terrones, N. Grobert, and H. Terrones, "Synthetic routes to nanoscale $\mathrm{B}_{\mathrm{x}} \mathrm{C}_{\mathrm{y}} \mathrm{N}_{\mathrm{z}}$ architectures," Carbon, vol. 40, no. 10, pp. 1665-1684, 2002.

[30] G. Baumgartner, M. Carrard, L. Zuppiroli, W. Bacsa, W. A. de Heer, and L. Forró, "Hall effect and magnetoresistance of carbon nanotube films," Physical Review B-Condensed Matter and Materials Physics, vol. 55, no. 11, pp. 6704-6707, 1997.

[31] M. R. Karim, "Synthesis and characterizations of poly(3hexylthiophene) and modified carbon nanotube composites," Journal of Nanomaterials, vol. 2012, Article ID 174353, 8 pages, 2012.

[32] J. Arranz-Andrés and W. J. Blau, "Enhanced device performance using different carbon nanotube types in polymer photovoltaic devices," Carbon, vol. 46, no. 15, pp. 2067-2075, 2008.

[33] F. Padinger, R. S. Rittberger, and N. S. Sariciftci, "Effects of postproduction treatment on plastic solar cells," Advanced Functional Materials, vol. 13, no. 1, pp. 85-88, 2003.

[34] K. Kim, J. Liu, M. A. G. Namboothiry, and D. L. Carroll, "Roles of donor and acceptor nanodomains in 6\% efficient thermally annealed polymer photovoltaics," Applied Physics Letters, vol. 90, no. 16, Article ID 163511, 2007.
[35] C. J. Brabec, N. S. Sariciftci, and J. C. Hummelen, "Plastic solar cells," Advanced Funtional Materials, vol. 11, no. 1, pp. 15-26, 2001.

[36] M. C. Scharber, D. Mühlbacher, M. Koppe et al., "Design rules for donors in bulk-heterojunction solar cells-towards $10 \%$ energy-conversion efficiency," Advanced Materials, vol. 18, no. 6, pp. 789-794, 2006.

[37] F. B. Kooistra, J. Knol, F. Kastenberg et al., "Increasing the open circuit voltage of bulk-heterojunction solar cells by raising the LUMO level of the acceptor," Organic Letters, vol. 9, no. 4, pp. 551-554, 2007.

[38] J. M. Holt, A. J. Ferguson, N. Kopidakis et al., "Prolonging charge separation in P3HT-SWNT composites using highly enriched semiconducting nanotubes," Nano Letters, vol. 10, no. 11, pp. 4627-4633, 2010.

[39] T. M. Clarke, F. C. Jamieson, and J. R. Durrant, "Transient absorption studies of bimolecular recombination dynamics in polythiophene/fullerene blend films," The Journal of Physical Chemistry C, vol. 113, no. 49, pp. 20934-20941, 2009.

[40] A. F. Nogueira, I. Montanari, J. Nelson et al., "Charge recombination in conjugated polymer/fullerene blended films studied by transient absorption spectroscopy," The Journal of Physical Chemistry B, vol. 107, no. 7, pp. 1567-1573, 2003.

[41] I.-W. Hwang, D. Moses, and A. J. Heeger, "Photoinduced carrier generation in $\mathrm{P} 3 \mathrm{HT} / \mathrm{PCBM}$ bulk heterojunction materials," The Journal of Physical Chemistry C, vol. 112, no. 11, pp. 4350-4354, 2008.

[42] H. Ohkita, S. Cook, Y. Astuti et al., "Charge carrier formation in polythiophene/fullerene blend films studied by transient absorption spectroscopy," Journal of the American Chemical Society, vol. 130, no. 10, pp. 3030-3042, 2008.

[43] L. Liu, W. E. Stanchina, and G. Li, "Effects of semiconducting and metallic single-walled carbon nanotubes on performance of bulk heterojunction organic solar cells," Applied Physics Letters, vol. 94, no. 23, Article ID 233309, 2009. 

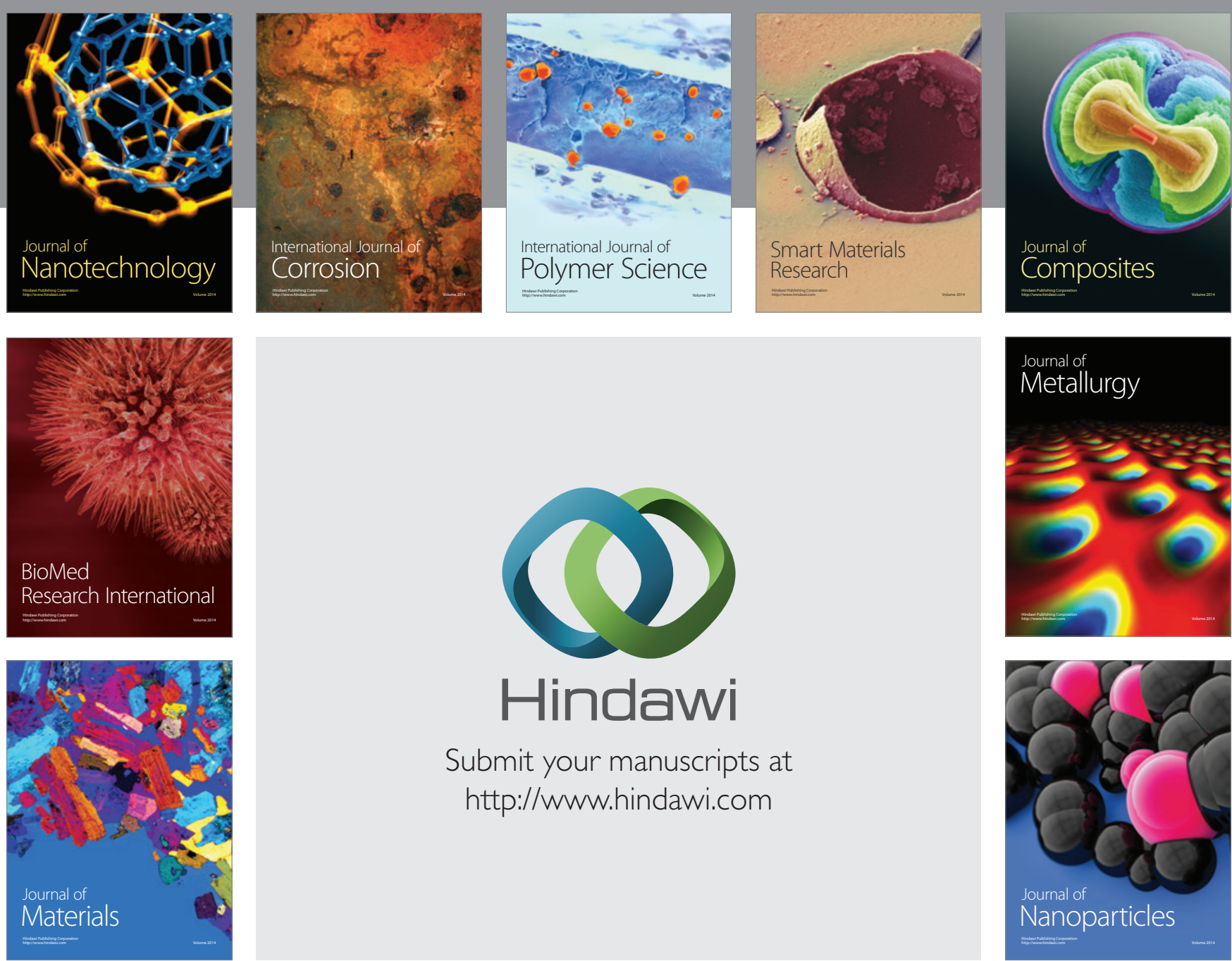

\section{Hindawi}

Submit your manuscripts at

http://www.hindawi.com

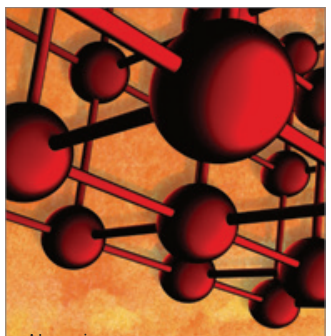

Materials Science and Engineering
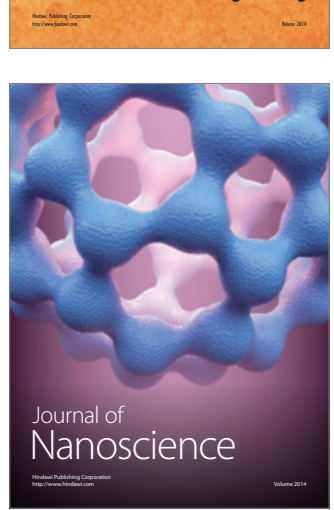
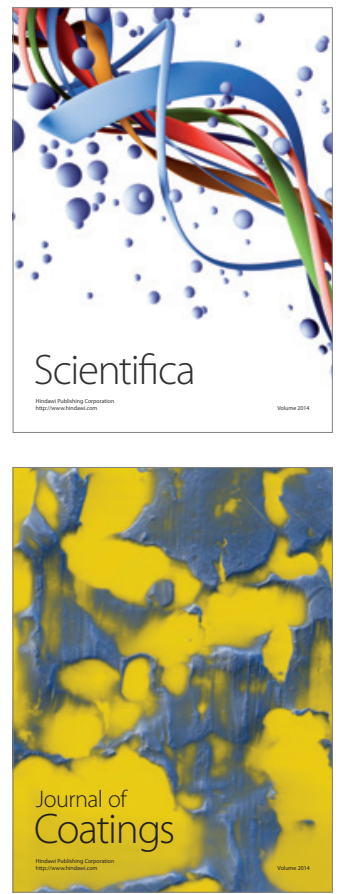
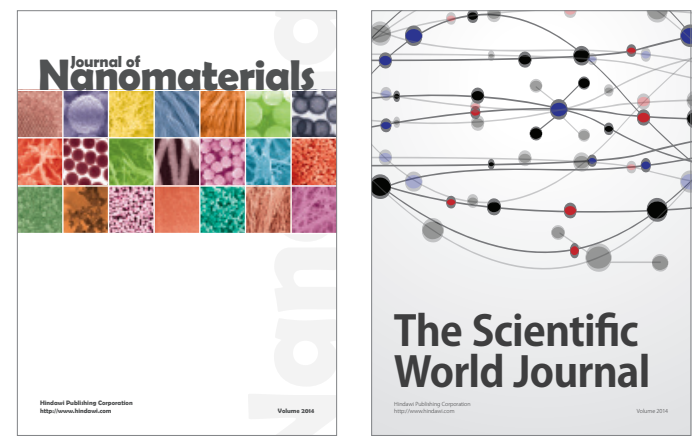

The Scientific World Journal
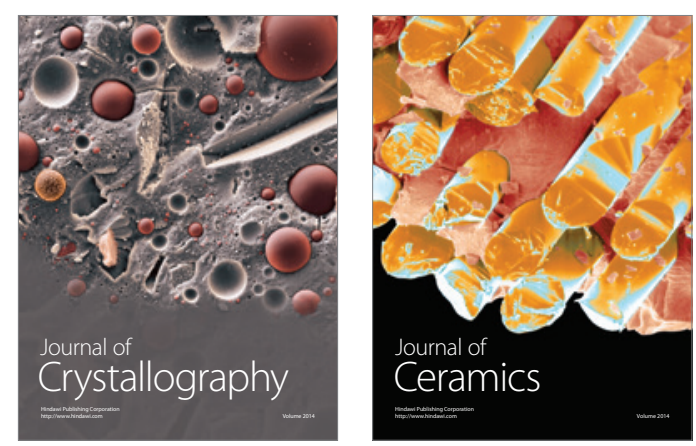
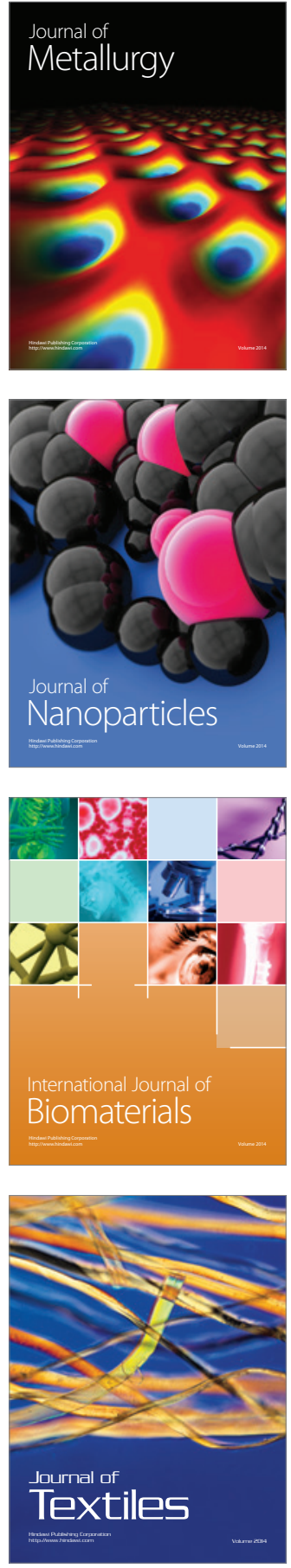